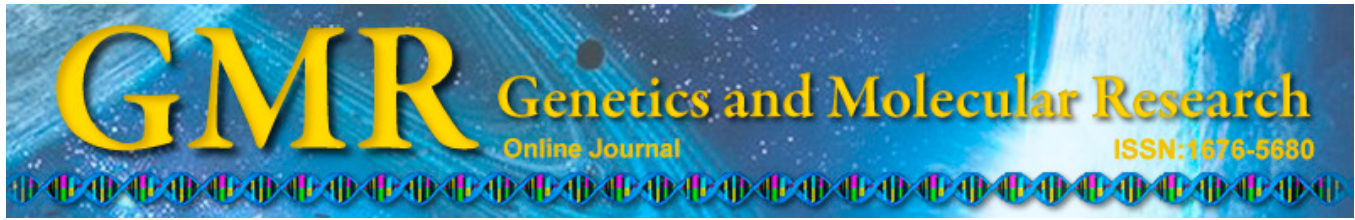

\title{
Protective effect of ischemia preconditioning on ischemia-reperfusion injury in rat liver transplantation
}

\author{
Z.S. Qing ${ }^{1 *}$, X.S. Zhang ${ }^{2 *}$, C.C. Gao ${ }^{3}$, W.D. Liu ${ }^{1}$, T.F. Xia ${ }^{1}$, K. Wu ${ }^{1}$ and \\ L.Q. Pang ${ }^{1}$
}

${ }^{1}$ Department of General Surgery, Huai'an First People's Hospital, Nanjing Medical University, Huai’an, Jiangsu, China

${ }^{2}$ Department of General Surgery, Lian'shui County People's Hospital, Lian'shui, Jiangsu, China

${ }^{3}$ Department of Gastroenterology, Huai' an First People's Hospital,

Nanjing Medical University, Huai'an, Jiangsu, China

*These authors contributed equally to this study.

Corresponding authors: L.Q. Pang / K. Wu

E-mail: LiqunPang@163.com / wukun_007@hotmail.com

Genet. Mol. Res. 14 (2): 3018-3025 (2015)

Received March 17, 2014

Accepted July 14, 2014

Published April 10, 2015

DOI http://dx.doi.org/10.4238/2015.April.10.12

\begin{abstract}
We explored the protective effect of ischemia preconditioning (IP) on ischemia-reperfusion injury in rat liver transplantation. An orthotopic liver transplantation model was utilized in the study. A total of 54 Sprague-Dawley rats were divided into a control group (group A, no liver transplantation), liver transplantation group (group B, heparin Ringer's lactate solution was perfused via the portal vein before donor liver collection), and liver transplantation with IP group (group C, IP was performed for different time periods before donor liver collection). Liver function, B-cell lymphoma 2 expression in hepatic cells, cell apoptosis, and cellular ultrastructure changes were detected after surgery. After surgery, serum alanine aminotransferase activity was significantly higher in group B than in group A, while it was not clearly enhanced in group $\mathrm{C}$ and decreased progressively with increasing cycles of IP as bile capacity gradually increased. Compared
\end{abstract}


with group B, group $\mathrm{C}$ showed alleviated injury of hepatic cells, increased B-cell lymphoma 2 expression, and a lower apoptosis index. IP had a protective effect on ischemia-reperfusion injury in rat liver transplantation, and the mechanism correlated with increased B-cell lymphoma 2 expression in hepatic cells and inhibition of cell apoptosis.

Key words: Ischemia preconditioning; Ischemia-reperfusion injury; Liver transplantation; Rats

\section{INTRODUCTION}

Ischemia preconditioning (IP) refers to one or more transient ischemia/reperfusion (I/R) episodes induced in body tissue or organs, which confers a state of endogenous protection of body tissue and cells against subsequent long-term ischemic injuries. During liver transplantation, primary hepatic non-function resulting from ischemia-reperfusion injuries (IRI) is considered to be the main reason for liver graft failure (Kupiec-Weglinski and Busuttil, 2005). In our study, the donor liver was subjected to IP and an orthotopic liver transplantation model was established; serological indicators, B-cell lymphoma 2 (Bcl-2) expression in liver tissue, cell apoptosis, and cellular ultrastructure changes were observed after IRI induction during rat liver transplantation to explore the protective effect of IP on the donor liver and to provide a theoretical basis for the clinical prevention and treatment of liver IRI in liver surgery and other fields.

\section{MATERIAL AND METHODS}

\section{Experimental animals}

A total of 54 healthy male Sprague-Dawley rats (from Laboratory Animal Center of Soochow University) were selected as donors and recipients. Rats had body weights of 220 $260 \mathrm{~g}$. The weights of recipients equaled or were slightly higher than those of donors.

\section{Methods}

After a 12-h preoperative fast with free access to water only, the rats were heparinized by injecting heparin through the dorsal vein of the penis, and then were intraperitoneally anesthetized with $80-100 \mathrm{mg} / \mathrm{kg}$ ketamine. Rats were randomly divided into 3 groups: control group (group A, 6 rats): an incision was made below the costal margin and the hepatic ligament was dissociated without blocking of the porta hepatis or other surgical treatment; liver transplantation group (group B, 12 rats): heparin Ringer's lactate solution was used for perfusion via the portal vein before donor liver collection; after $2 \mathrm{~h}$ of preserving the liver at $4^{\circ} \mathrm{C}$ in Ringer's lactate solution, orthotopic liver transplantation was performed using the 2-cuff technique (anhepatic phase was approximately $14 \mathrm{~min}$ ) (Kamada and Calne, 1983); liver transplantation with IP group (group C, 36 rats): donor livers were subjected to IP, and heparin Ringer's lactate solution was used for perfusion via the portal vein before liver collection; after $2 \mathrm{~h}$ of preservation of the liver at $4^{\circ} \mathrm{C}$ in Ringer's lactate solution, orthotopic liver transplantation was conducted. Group $\mathrm{C}$ was divided into 3 subgroups (12 rats in each group) according to different IP cycles: group C1 (1 cycle), group C2 (2 cycles), and group C3 (3 
cycles). One cycle of IP was conducted with interruption of the first hepatic portal for $5 \mathrm{~min}$, and reflow was initiated by removing the clamp on the liver for another $5 \mathrm{~min}$. Six hours after surgery, samples were collected for the detection of various indicators.

\section{Detection of biochemical indicators and bile capacity}

For the biochemical indicator test, $1 \mathrm{~mL}$ blood was collected from the inferior vena cava; serum alanine aminotransferase (ALT), aspartate transaminase (AST), and lactate dehydrogenase (LDH) were analyzed using an automatic biochemical analyzer. To measure bile secretion, an epidural catheter was inserted into the proximal common bile duct to measure the length of the catheter through which the bile flowed within $1 \mathrm{~min}$. For catheter volume determination, $50 \mu \mathrm{L}$ colored liquid was injected into the catheter using a microsyringe and the length was measured 6 times; $1 \mathrm{~mm}=0.65 \pm 0.26 \mu \mathrm{L}$.

\section{Cell apoptosis assay}

Terminal deoxynucleotidyl transferase dUTP nick-end labeling was performed according to kit manufacturer instructions (Roche, Basel, Switzerland). Five fields at 400X magnification were randomly selected from each section; the average number of apoptotic cells in 1000 cells was calculated and reported as percentage (apoptosis index: AI).

\section{Bcl-2 expression in hepatic cells}

The immunohistochemical SP method (Boster Immunoleader, Fremont, CA, USA) was employed to detect Bcl-2 expression; at high magnification, cells with brown cytoplasm were considered to be Bcl-2-positive. Five fields at $400 \mathrm{X}$ magnification were randomly selected; the number of positively stained cells in 1000 hepatic cells was counted as the Bcl-2 expression index.

\section{Subcellular morphology observation}

Liver tissue samples of $1 \mathrm{~mm}^{3}$ were fixed in $4 \%$ glutaraldehyde; the tissue section was prepared according to the requirement of the transmission electron microscope and was doublestained with uranium acetate/lead nitrate, followed by observation under an electron microscope.

\section{Statistical analysis}

Data are reported as means \pm standard deviation; analysis of variance was performed using the SAS 9.1.3 statistical software (SAS Institute, Cary, NC, USA); $\mathrm{P}<0.05$ was considered to be statistically significant.

\section{RESULTS}

\section{Activity of serum ALT, AST, and LDH and change in bile capacity}

The results are shown in Table 1. Compared with group A, group B showed signifi- 
cantly higher serum ALT, AST, and LDH activity, but distinctly lower bile capacity per minute $(\mathrm{P}<0.01)$; various indicators of group $\mathrm{C} 2$ and $\mathrm{C} 3$ improved markedly compared with those of group $\mathrm{C} 1$ and $\mathrm{B}$, which showed similar values; in group $\mathrm{C}$, the indicators clearly improved with increasing IP cycles $(\mathrm{P}<0.01$ or 0.05$)$.

Table 1. Bile capacity and activity analysis of ALT, AST, and LDH in serum in different groups.

\begin{tabular}{lrcccc}
\hline Group & $\mathrm{N}$ & $\mathrm{ALT} z_{\mathrm{B}} /(\mathrm{U} / \mathrm{L})$ & $\mathrm{AST} z_{\mathrm{B}} /(\mathrm{U} / \mathrm{L})$ & $\mathrm{LDH} z_{\mathrm{B}} /(\mathrm{U} / \mathrm{L})$ & $\mathrm{Bile}\left(\mu \mathrm{L} \cdot \mathrm{min}^{-1} \cdot \mathrm{g}^{-1}\right)$ \\
\hline A & 6 & $32.32 \pm 8.76$ & $198.67 \pm 15.49$ & $2,563.58 \pm 246.27$ & $9.52 \pm 1.38$ \\
B & 12 & $1,636.73 \pm 215.39^{* *}$ & $2,833.54 \pm 294.76^{* *}$ & $5,970.89 \pm 475.37 * *$ & $3.12 \pm 0.79^{* *}$ \\
C1 & 12 & $1,458.55 \pm 264.62^{* *}$ & $2,485.56 \pm 252.28^{* *}$ & $5,446.42 \pm 340.68^{* *}$ & $3.79 \pm 0.93^{* *}$ \\
C2 & 12 & $797.63 \pm 163.75^{* * \Delta}$ & $1,978.68 \pm 270.52^{* * \Delta}$ & $4,945.27 \pm 383.89^{* * \Delta}$ & $5.18 \pm 1.12^{* * \Delta}$ \\
C3 & 12 & $187.16 \pm 63.08^{* * \Delta \Delta \Delta}$ & $756.28 \pm 96.35^{* * \Delta \Delta \Delta \Delta}$ & $3,567.27 \pm 195.36^{* * \Delta \Delta}$ & $8.72 \pm 1.16^{\Delta \Delta \Delta}$ \\
\hline
\end{tabular}

A: Control group $(\mathrm{N}=6)$. Without operation of liver transplantation; B: liver transplantation $(\mathrm{N}=12)$. After donor livers were preserved for $2 \mathrm{~h}$ at $4^{\circ} \mathrm{C}$ in Ringer's lactate solution, rat orthotopic liver transplantation was performed using the cuff technique; $\mathrm{C} 1, \mathrm{C} 2, \mathrm{C} 3$ : ischemic precondition groups $(\mathrm{N}=12)$. After grafts under ischemic preconditions were harvested and then preserved for $2 \mathrm{~h}$ at $4^{\circ} \mathrm{C}$ in Ringer's lactate solution, rat orthotopic liver transplantation was performed. Portal veins and hepatic arteries of rat livers were interrupted for 5 min and then reflow was initiated for another $5 \mathrm{~min}$, which was regarded as 1 cycle. $\mathrm{C} 1, \mathrm{C} 2$, and $\mathrm{C} 3$ animals were subjected to 1 , 2, and 3 cycles, respectively. ${ }^{* *} \mathrm{P}<0.01$ vs group $\mathrm{A} ;{ }^{\triangle} \mathrm{P}<0.05, \triangle \triangle \mathrm{P}<0.01$ vs group $\mathrm{B} ;{ }^{\Delta} \mathrm{P}<0.05,{ }^{\Delta}{ }^{\Delta} \mathrm{P}<0.01$ vs group $\mathrm{C} 2$.

\section{Cell apoptosis and Bcl-2 expression in hepatic tissue}

AI in group $\mathrm{B}$, which was clearly higher than that in group $\mathrm{A}(\mathrm{P}<0.01)$, was not significantly different from that in group $\mathrm{C} 1$. AI in groups $\mathrm{C} 2$ and $\mathrm{C} 3$ was dramatically reduced compared with that in group $\mathrm{B}(\mathrm{P}<0.01)$, but remained higher than that in group $\mathrm{A}(\mathrm{P}<0.05$ or 0.01). Bcl-2 expression in hepatic tissue was higher in group B compared with that in group $\mathrm{A}(\mathrm{P}<0.01)$. In group $\mathrm{C}, \mathrm{Bcl}-2$ protein expression was gradually elevated along with increasing IP cycles; no statistical difference was observed between groups $\mathrm{C} 1$ and $\mathrm{B}$, while groups $\mathrm{C} 2$ and $\mathrm{C} 3$ displayed enhanced Bcl-2 protein expression compared with group $\mathrm{B}(\mathrm{P}<0.05$ or 0.01). Specific data are shown in Table 2.

Table 2. Apoptotic index and Bcl-2 expression in liver in different groups (\%).

\begin{tabular}{|c|c|c|c|}
\hline Group & $\mathrm{N}$ & Apoptotic index & Bcl-2 \\
\hline A & 6 & $1.87 \pm 0.63$ & $0.17 \pm 0.05$ \\
\hline B & 12 & $22.78 \pm 4.56^{* *}$ & $1.18 \pm 0.76^{* *}$ \\
\hline $\mathrm{C} 1$ & 12 & $18.35 \pm 3.66^{* *}$ & $1.85 \pm 0.89 * *$ \\
\hline $\mathrm{C} 2$ & 12 & $11.17 \pm 2.07 * * \triangle \triangle$ & $2.35 \pm 1.12^{* * \Delta}$ \\
\hline $\mathrm{C} 3$ & 12 & $3.68 \pm 1.37 * \Delta \triangle \Delta \Delta$ & $5.26 \pm 1.57 * * \Delta \triangle \Delta \triangle$ \\
\hline
\end{tabular}

\section{Observation of pathological morphology on liver tissue}

\section{Microscopic observation}

In group A, hepatic cells and liver sinusoidal endothelial cells were normal; the structures of the hepatic lobule, central veins, and portal area were clear (Figure 1A). In group B, congestion and stenosis were observed in the central vein of the hepatic lobule and hepatic 
sinusoid, and hepatic cells showed different degrees of swelling and degeneration (Figure 1B). In group $\mathrm{C} 3$, hepatic congestion was alleviated compared with that in group B; the structures of hepatic lobule, portal area, central veins, and sinusoidal cable were normal and clear without deformation. Hepatic cells were slightly swelled (Figure 1C).

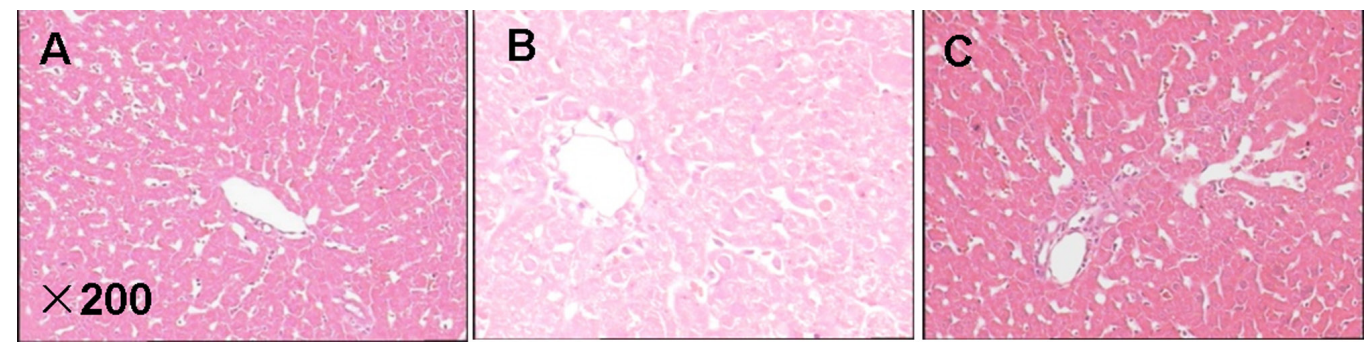

Figure 1. Pathology of liver tissue (H-E). A. Normal hepatic cell in group A. B. Hepatocellular swell, transformation of vacuoles in group B. C. Normal hepatic tissue in group C3. Original magnification: 200X.

\section{Transmission electron microscopy observation}

In group A, the organelle structure was intact with neatly arranged mitochondria (Figure 2A). In group B, mitochondria swelling with arrangement disorder and reduced cristae, cytoplasm rarefaction, more lysosome, chromosome margination, and deformation of the cell membrane and nuclear membrane as well as apoptotic cells and bodies were observed (Figure 2B and C). In group C3, hepatic cell injury was significantly alleviated and cellular ultrastructure was relatively normal; mitochondria were mildly swelled and cytoplasmic vacuoles were occasionally observed (Figure 2D and E).

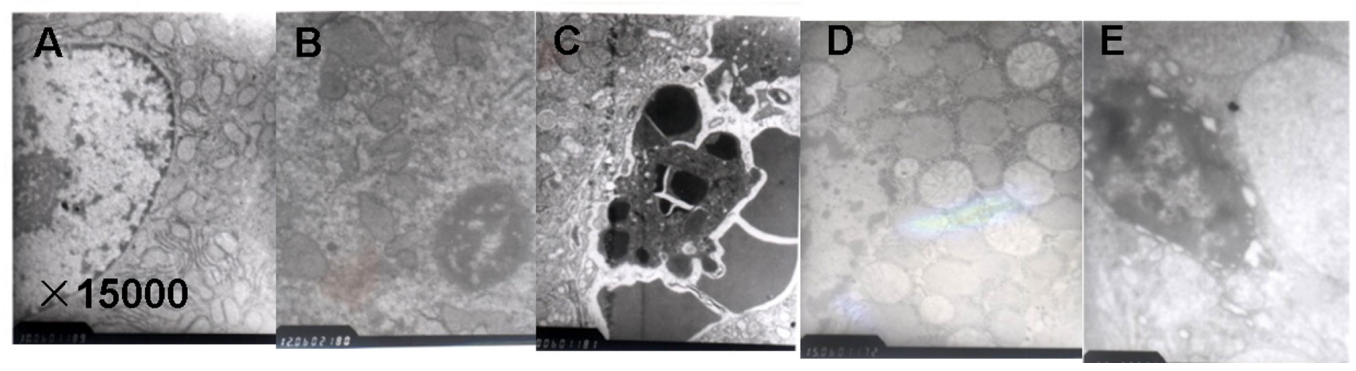

Figure 2. SEM results of liver tissue. A. Normal hepatic cell in group A. B. Hepatocellular apoptosis in group B. C. Endothelial cell apoptosis in group B. D. Mitochondria swell in group C3. E. Chromosome border, transformation of vacuoles in group C3. Original magnification: 15,000X.

\section{DISCUSSION}

\section{Protective effect of IP on the donor liver}

During liver transplantation, IRI is inevitable; parenchymal hepatic cells and liver sinusoidal endothelial cells are not only characterized by edema, degeneration, and necrosis, but also show significant apoptosis (Huet et al., 2004; Kaszaki et al., 2006). A number of interventions are currently used to protect organs from IRI. IP was recently developed as a simple but 
effective preprocessing method, which has certain clinical significance and protective effects on IRI of the brain, lung, and liver (Waldow et al., 2004; Gao et al., 2006; Szijártó, 2008). No studies have examined whether repeated interruption of the hepatic portal vein, i.e., extending the period of liver without blood, and the application of IP to the donor liver not only ensure successful surgery, but also protect the transplanted liver. Therefore, we designed an animal model in which multiple hepatic portal interruptions of the donor liver was performed over a short time before liver transplantation to explore the feasibility of this hypothesis by observing the postoperative activity of serum ALT, AST, and LDH and bile capacity per minute, as well as cell apoptosis and pathologic changes in hepatic tissue in the transplantation group.

Our results showed that along with increasing IP cycles, serum ALT, AST, and LDH activities and $\mathrm{AI}$ in rats with liver transplantation progressively decreased, and that pathological changes in the cell structure in liver tissues were also gradually ameliorated. The experimental results displayed that multiple IP cycles of the donor liver could distinctly alleviate IRI, maintain basic cell structure and function, and protect IRI-induced donor liver dysfunction after transplantation. However, whether the number of IP cycles and the time period require optimization for clinical application according to the liver pathologic condition of patients requires further investigation.

\section{Possible mechanisms of the protective effect of IP on the donor liver}

The basis for liver IRI includes oxyradical injury, energy failure, and microcirculation disturbance, and their morphological features of the secondary injury include cell necrosis and apoptosis, which are closely correlated with the degree of liver damage (Fondevila et al., 2003; Liang et al., 2003). IP has a significant protective effect on IRI of transplanted liver, but the underlying mechanism remains unclear. The protective mechanisms are thought to be associated with elevated adenosine and nitric oxide levels, tumor necrosis factor- $\alpha$ elimination, and changes in energy metabolism and maintenance of microcirculation (Ma et al., 2001; Zhang and Chen, 2004; Lee and Lee, 2006).

Our results showed that Bcl-2 is lowly expressed in normal liver tissue, but highly expressed after liver transplantation, which may be involved in the protective reaction of liver tissue. In the IP group, Bcl-2 expression was enhanced along with the increase in IP cycles, which is negatively correlated with AI and positively correlated with various indicators of liver function. This indicates that IP induced Bcl-2 overexpression in transplanted liver during the pathological process of liver IRI to inhibit hepatic cell apoptosis; this was likely an important protective mechanism of IP (Kienle et al., 2005).

The Bcl-2 protein localizes to the nuclear membrane, rough endoplasmic reticulum, and mitochondrial membrane and plays an important role in cell apoptosis induced by various stimuli (Oshiro et al., 2002; Mueller et al., 2004): 1) Bcl-2 overexpression reduces the production of oxygen radicals and the formation of lipid peroxide; 2) Bcl-2 inhibits $\mathrm{Ca}^{2+}$ flow across the membrane and apoptosis by regulating intracellular calcium ion concentration; 3) Bcl-2 dimerizes with other proteins of the Bcl-2 family such as Bcl-Xl, the Bcl-Xs, Bax, Bcl-2, Bad, and Mcl-1 to inhibit cell apoptosis as a molecular switch for cell death signaling pathways; and 4) Bcl-2 acts upstream of caspase-3 and terminates the caspase cascade induced by different pathological factors by inhibiting the permeability of the mitochondrial membrane and release of cytochrome C, suppressing cell apoptosis (Salakou et al., 2007; Gao et al., 2013). Caspase-3 is thought to play the most important role in the caspase family, which regulates 
digestion of all crucial enzymes and activates substrates. IP resulted in a significant decrease in p38 MAPK activation at the end of reperfusion when compared to non-preconditioned organ. This was accompanied by a significant decrease in apoptosis as measured with caspase-3 activation (Moolman et al., 2006). Upregulation of Bcl-2 expression can terminate the activation of caspase- 3 through a variety of apoptotic signals and inhibit the apoptotic effect of apoptosis-stimulating factors induced by IRI on cells (Wu et al., 2011; Ko et al., 2013).

In conclusion, the apoptosis of parenchymal hepatic cells occurs during liver IRI during liver transplantation and the inhibitory regulation of cell apoptosis can reduce these injuries. Preoperative IP cycles of the donor liver can induce hepatic cells to highly express Bcl-2, suppress cell apoptosis caused by various pathological factors after liver transplantation and reperfusion, maintain basic cell structure and function, distinctly alleviate IRI, and decrease the incidence of primary hepatic non-function after transplantation. Our results also provide an experimental basis for exploring IP methods in clinical liver surgery.

\section{ACKNOWLEDGMENTS}

Research supported by the Supporting Technology Foundation of Huai'an Municipal Technology Bureau (\#HG201112,\#HG2014013) and the Science and Technology Development Fund of Najing Medical University (\#2010NJMUZ08).

\section{REFERENCES}

Fondevila C, Busuttil RW and Kupiec-Weglinski JW (2003). Hepatic ischemia/reperfusion injury - a fresh look. Exp. Mol. Pathol. 74: 86-93.

Gao C, Chai W, Xu L, Zhang H, et al. (2006). Protective effects of hyperoxygenated solution preconditioning on intestinal ischemia-reperfusion injury in rabbits. J. Surg. Res. 135: 268-274.

Gao J, Zhao L, Wang Y, Teng Q, et al. (2013). Effect of limb ischemic preconditioning on myocardial apoptosis-related proteins in ischemia-reperfusion injury. Exp. Ther. Med. 5: 1305-1309.

Huet PM, Nagaoka MR, Desbiens G, Tarrab E, et al. (2004). Sinusoidal endothelial cell and hepatocyte death following cold ischemia - warm reperfusion of the rat liver. Hepatology 39: 1110-1119.

Kamada N and Calne R (1983). A surgical experience with five hundred thirty liver transplants in the rat. Surgery 93: 64-69.

Kaszaki J, Wolfárd A, Szalay L and Boros M (2006). Pathophysiology of Ischemia-Reperfusion Injury. Transplant Proc. Elsevier, Amsterdam, 826-828.

Kienle K, Rentsch M, Müller T, Engelhard N, et al. (2005). Expression of BCL-2 in Liver Grafts After Adenoviral Transfer Improves Survival Following Prolonged Ischemia and Reperfusion in Rat Liver Transplantation. Transplant Proc. Elsevier, Amsterdam, 439-441.

Ko JS, Gwak MS, Kim GS, Shin YH, et al. (2013). The Protective Effect of Ischemic Preconditioning Against Hepatic Ischemic-Reperfusion Injury Under Isoflurane Anesthesia in Rats. Transplant Proc. Elsevier, Amsterdam, 1704-1707.

Kupiec-Weglinski J and Busuttil R (2005). Ischemia and Reperfusion Injury in Liver Transplantation. Transplant Proc. Elsevier, Amsterdam, 1653-1656.

Lee WY and Lee SM (2006). Synergistic protective effect of ischemic preconditioning and allopurinol on ischemia/ reperfusion injury in rat liver. Biochem. Biophys. Res. Commun. 349: 1087-1093.

Liang TB, Man K, Lee TKW, Hong-Teng Tsui S, et al. (2003). Distinct intragraft response pattern in relation to graft size in liver transplantation. Transplantation 75: 673-678.

Ma K, Yu Y, Bu XM, Li YJ, et al. (2001). Prevention of grafted liver from reperfusive injury. World J. Gastroenterol. 7: 572-574.

Moolman JA, Hartley S, Van Wyk J, Marais E, et al. (2006). Inhibition of myocardial apoptosis by ischaemic and betaadrenergic preconditioning is dependent on p38 MAPK. Cardiovasc. Drugs Ther. 20: 13-25.

Mueller TH, Kienle K, Beham A, Geissler EK, et al. (2004). Caspase 3 inhibition improves survival and reduces early graft injury after ischemia and reperfusion in rat liver transplantation. Transplantation 78: 1267-1273.

Oshiro T, Shiraishi M and Muto Y (2002). Adenovirus mediated gene transfer of antiapoptotic protein in hepatic ischemia- 
reperfusion injury: The paradoxical effect of Bcl-2 expression in the reperfused liver. J. Surg. Res.103: 30-36.

Salakou S, Kardamakis D, Tsamandas AC, Zolota V, et al. (2007). Increased Bax/Bcl-2 ratio up-regulates caspase-3 and increases apoptosis in the thymus of patients with myasthenia gravis. In Vivo 21: 123-132.

Szijártó A (2008). Methods of increasing ischemic tolerance in liver surgery. Magy. Seb. 61: 128-135.

Waldow T, Alexiou K, Witt W, Wagner FM, et al. (2004). Protection of lung tissue against ischemia/reperfusion injury by preconditioning with inhaled nitric oxide in an in situ pig model of normothermic pulmonary ischemia. Nitric Oxide 10: 195-201.

Wu Q, Tang C, Zhang YJ, Jiang Y, et al. (2011). Diazoxide suppresses hepatic ischemia/reperfusion injury after mouse liver transplantation by a BCL-2-dependent mechanism. J. Surg. Res. 169: e155-e166.

Zhang SJ and Chen S (2004). The Role of Ischemic Preconditioning in Rat Liver Graft. Transplant Proc. Elsevier, Amsterdam, 1970-1972. 